\title{
A New Low-protein Foodstuff from Processed Brown Rice for Chronic Kidney Disease
}

\section{Shaw Watanabe ${ }^{1 *}$, Satoshi Minakuchi ${ }^{2}$, Masaki Yamaguchi ${ }^{3}$, Hiromasa Uchiyama $^{4}$, Tomitsu Haramoto ${ }^{5}$, Kazunori Egawa ${ }^{6}$, Ken'ichi Otsubo ${ }^{7}$ and Azusa Hirakawa ${ }^{1}$}

${ }^{1}$ Tokyo University of Agriculture, Agricultural Life Science Institute, Setagaya,

Tokyo, Japan

${ }^{2}$ Ehime Research Institute of Agriculture, Forestry and Fisheries, Ehime, Japan

${ }^{3}$ Biotec Japan, Niigata, Japan

${ }^{4}$ Forica Co. Ltd., Niigata, Japan

${ }^{5}$ Tomitsu Haramoto, Kanagawa, Japan

${ }^{6}$ Egawa Technical Office, Niigata, Japan

${ }^{7}$ Niigata University of Pharmacy and LifeScience, Niigata, Japan

*Corresponding Author: Shaw Watanabe, President, Medical Rice Association,

Visiting Professor, Tokyo University of Agriculture, Japan.
Received: July 07, 2021

Published: July 19, 2021

(C) All rights are reserved by Shaw Watanabe., et al.

\begin{abstract}
Aims: Chronic kidney disease (CKD) is increasing in prevalence worldwide, not only as a complication of diabetes and end-stage glomerulonephritis but also as a typical degenerative process in the elderly. A low-protein diet is essential for the prevention and delay of CKD. As rice is the leading staple food in many countries, low-protein rice should be considered for dietary therapy. Brown rice, in particular, contains many functional factors for health, so that low-protein brown rice could provide additional benefits for CKD patients.

Methods: Four steps are necessary to produce low-protein brown rice of high quality: selection of rice cultivar, surface treatment of brown rice with a penetrating enzyme solution, protein extraction, and hygienic packaging. We developed a new low-protein brown rice (LPBR) product using protease treatment and Lactobacillus plantarum fermentation.

Results: LPBR maintained the high energy content of rice. While it provided the lowest protein content possible $(0.2 \mathrm{~g} / 100 \mathrm{~g}$ of boiled rice), almost no potassium ( $0.5 \mathrm{mg} / 100 \mathrm{~g}$ boiled rice), and less than $1 / 5$ of usual phosphate contents (17 mg/100 g boiled rice). In addition, toxic metals such as antimony and cadmium were not present. Like common brown rice brands, the new product had high dietary fibers $(1.0 \mathrm{~g} / 100 \mathrm{~g}$ boiled rice), $\gamma$-oryzanol $(6.3 \mathrm{mg} / 100 \mathrm{~g}$ boiled rice), and antioxidant activity (300 ORAC Unit). Conclusion: A low-protein diet has been known to be effective for the prevention of CKD. LPBR could provide enough energy with low protein, low potassium, low phosphate. Furthermore, the remaining dietary fibers, $\gamma$-oryzanol, and antioxidant activity could have sound effects to stabilize intestinal microbiota, short-chain fatty acids, and innate immunity.
\end{abstract}

Keywords: Low-protein Brown Rice; Lactobacillus; Enzyme Solution; Chronic Kidney Disease; Dietary Therapy; Himeiku-83

\section{Abbreviation}

LPBR: Low Protein Brown Rice.

\section{Introduction}

The global burden of chronic kidney disease (CKD) is an essential public-health matter because of its progression to end-stage 
and the resulting extra healthcare costs [1-5]. The prevalence of CKD is estimated to be $8-16 \%$ worldwide, and it is linked to other major lifestyle-related diseases, such as diabetes mellitus, cardiovascular diseases, and hypertension [6-10]. CKD is defined as a reduced glomerular filtration rate (GFR), an increased urinary albumin excretion, or both [1,2]. Recently, diabetes mellitus has become the most common cause of CKD [6]. Diabetic kidney disease (DKD) occurs in $20 \%$ to $40 \%$ of patients with diabetes mellitus. It is the leading cause of CKD and ESRD in the United States [9] and Japan.

The economic costs of CKD are expected to reach enormous amounts, and strategies to delay the onset or progression are urgently required. Recently the occurrence of CKD has been increasing among the elderly. The cumulative risk of hemodialysis until age 80 years is $1 / 50$ in males and 1/100 in females [10]. Therefore, it is imperative to delay the conditions that make hemodialysis necessary to decrease medical costs and improve patients' quality of life. Dietary control is essential. The recommended dietary daily intake of proteins is $0.8 \mathrm{~g} / \mathrm{kg}$ body weight, representing an average of $60 \mathrm{~g} /$ day for men and $50 \mathrm{~g} /$ day for women [11].

A Cochrane review has concluded that we would set the optimal protein intake for CKD patients at $0.4-0.6 \mathrm{~g} / \mathrm{kg}$ body weight [12]. According to the Japanese Guidelines of the Kidney Association for CKD, it is $0.6-0.8 \mathrm{~g} / \mathrm{kg}$ body weight, and the recommended protein intake during hemodialysis is $1.2-1.5 \mathrm{~g} / \mathrm{kg}$ body weight [13]. The amount of protein intake to suppress CKD progression is still in debate. We propose that $0.5 \mathrm{~g} / \mathrm{kg}$ body weight is adequate, in line with Cochrane's recommendation. Unique tailor-made design is necessary for advanced CKD patients.

As rice is the staple food in Japan, low-protein white rice with less than $1 / 2$ protein content has been recommended for some patients [14]. However, the taste and texture of the initial preparations were not satisfactory. Brown rice contains six times more dietary fibers in weight than polished rice and more minerals and vitamins. However, the protein content was still high (6-8\%) and was covered by a strong wax layer. In addition, brown rice is usually contaminated with aerobic spores and other germs inside the grain epidermis. These represent technical obstacles to the preparation of low-protein brown rice (LPBR) [15]. We have established that the selection of four steps was essential: rice cultivars, proper grain surface treatment, selection of enzyme solution to extrude rice proteins, and packing method. We challenged to produce an ideal LPBR, characterized by low protein, low potassium, low phosphate, remaining dietary fiber, $\gamma$-oryzanol and anti-oxidant activity, by the consortium on the platform of the Ministry of Agriculture, Forestry and Fisheries.

\section{Materials and Methods}

Rice

Rice proteins are constituted by easily digestible glutelin and globulin and indigestible prolamin [16,17]. So far, low-gluterin rice, such as the Shunyo and LGC-jun varieties developed in Japan, have a taste that disturb their use in an ordinary diet. A newly established species of paddy rice, "Himeiku-83" (Ehime Research Institute of Agriculture, Forestry and Fisheries), was selected for this project. This new variety was a hybrid between "Chugoku-188" as mother and "Himeiku-71" as the father. Chugoku-188 had both the Lgc1 gene, which decreased glutelin, and the glb1 gene, which deprived globulin (Figure 1). As compared with Shunyo and LGCjun, Himeiku-83 had a better taste and good grain qualities. The taste evaluation score by the Japan Grain Inspection Association was high. The taste of Himeiku-83 was as delicious as Koshihikari. The yield of Himeiku-83 was higher than that of Hinohikari. The protein contents of brown rice are $6.3 \%-7.0 \%$. The variety registration was applied on November 9, 2020 [18].

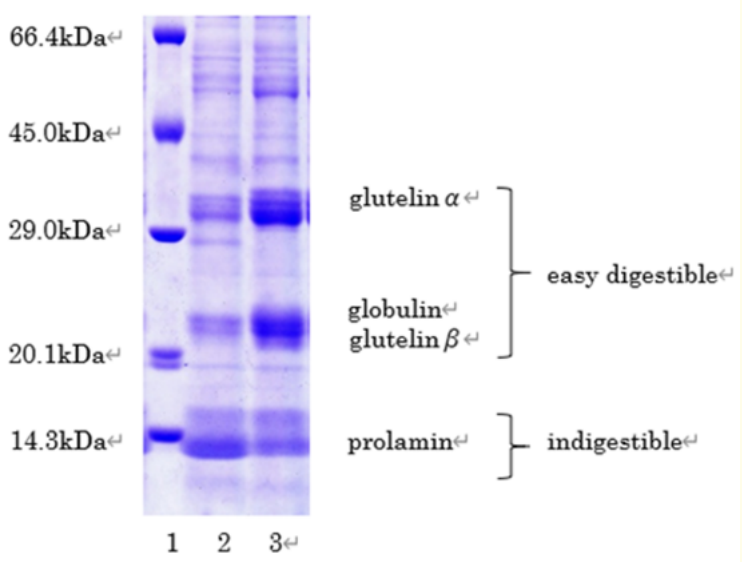

Figure 1: SDS-PAGE pattern of proteins in brown rice.

Himeiku-83 shows less amount of easy digestible glutelins and globulin.

\section{Pretreatment and protein extraction}

The purpose of the polishing process was to damage the wax layer of the surface of brown rice [19]. It is intended to perform less than $1 \%$ refinement at the Mitsuhashi Co. Ltd. to make fine scratch- 
es on the surface. The surface of brown rice showed fine scratches, and the rice seemed to be glassy white.

\section{Protein extraction}

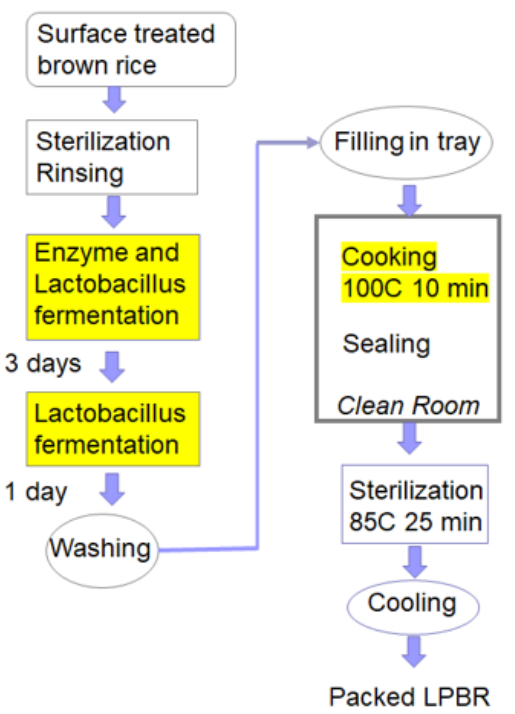

Figure 2: Serial steps to produce a low-protein brown rice.

Extraction of protein included two-step of fermentation. The sterilized rice was immersed in a solution containing the proteolytic enzyme "Protease M (Amano) G" and Lactobacillus plantarum as primary fermentation agent under anaerobic conditions.

For processing into packed rice, trays containing one serving ( $99 \mathrm{~g}$ ) of fermented brown rice were steamed for 10 minutes in a steamer, added $58 \mathrm{ml}$ of hot water $\left(70^{\circ} \mathrm{C}\right)$, and steamed again. After cooking, a seal was put in the hot state.

As it is known that heat-stable bacteria (such as Bacillus sp.) are present near the aleurone layer of brown rice [20], the epidermis (pericarp and seed coat) was sterilized and washed for damaged brown rice. In the sterilization and cleaning process, polished brown rice was placed in $2 \%$ aqueous citric acid solution, heated to $70^{\circ} \mathrm{C}$, and stirred to remove impurities, germs, and stains adhering to the surface. Quality control includes three cycles of detection of contamination with heat-resistant bacteria in the processed LPBR packs. The final products showed the absence of living bacilli, coliforms sp., Bacillus cereus sp., heat-resistant aerobic, and anaerobic bacilli [21].
Extraction of protein included two-step of fermentation (Figure 2). After sterilizing and cleaning the surface by citric acid solution, the sterilized rice was immersed in a solution containing the proteolytic enzyme "Protease M (Amano) G" and Lactobacillus plantarum as primary fermentation agent under anaerobic conditions [15]. The rice was fermented for three days at $40^{\circ} \mathrm{C}$. After draining, a secondary anaerobic fermentation was performed by the same Lactobacillus-containing solution for 1.5 days at $40^{\circ} \mathrm{C}$. Then it was washed with water to remove surplus, and after washing with cold water again, we drained it again.

After the fermentation process, a removal cleaning process was performed, involving draining the secondary fermentation. After that, wash with running water for 2 hours, and fermentation products such as organic acids and proteins generated during fermentation were washed away with decomposing substances and residual lactic acid bacteria. After the removal and washing treatment, the protein content was measured by the Dumas method.

Packing

For processing into packed rice, trays containing one serving ( $99 \mathrm{~g}$ ) of fermented brown rice were steamed for 10 minutes in a steamer, added $58 \mathrm{ml}$ of hot water $\left(70^{\circ} \mathrm{C}\right)$, and steamed again. After cooking, a seal was put in the hot state. Each package was sterilized by immersion in a constant temperature water tank at $85^{\circ} \mathrm{C}$ for 25 minutes and then cool. We kept the $\mathrm{pH}$ of the final product of the packed rice at 4.25 by spraying $0.1 \%$ gluconic acid [21].

\section{Measurement}

The boiled and immediately frozen rice was sent to the Nippon Food Analysis Center, Tsukuba, Japan, for nutrients measurement [22], such as energy, major nutrients, vitamins, minerals, and $\gamma$-oryzanol. These were measured according to the Ministry of Agriculture, Forestries and Fisheries guidelines.

SUNTEC Research Laboratories measured the following; vitamin B1, minerals (calcium, phosphate, iron, sodium, potassium, magnesium, zinc, copper, selenium, manganate), and 28 amino acids. Antimony and cadmium were assessed to confirm safety [23]. These were single measurement from a single rice pack. Cooked brown rice and LPBR were compared and residual percent after protein extraction was calculated.

Antioxidant activity was measured by a modified method of Oxygen Radical Absorbance Capacity (ORAC) by the AOU Research 
Association. ORAC measurement used 6-hydroxy-2,5,7,8-tetramethylchroman-2-carboxylic acid (Trolox) as a standard antioxidant capacity sample and was expressed as Trolox equivalent [24]. Water-soluble and lipid-soluble AOU (ORAC) were separately measured [25-27].

\section{Results}

Major nutrients and antioxidant activity in LPBR

Macronutrients and other ingredients are shown in table 1. Among the several different ways Biotech2020 showed the best results (data not shown). A slight reduction in energy source was caused by immersion of cooking water, which made soft palatability like polished white rice. The remaining protein was $15 \%(0.2$ $\mathrm{g} / 100 \mathrm{~g}$ boiled rice). Ninety nine percent potassium and $85 \%$ phosphate were removed. Dietary fibers and $\gamma$-oryzanol remained twothird of brown rice $(1.0 \mathrm{~g}$ and $6.3 \mathrm{mg} / 100 \mathrm{~g}$ boiled rice, respectively). Water-soluble fibers seemed to be more easily resolved than insoluble dietary fibers during the processing. As for other micronutrients, the reduction of minerals was characteristic in LPBR. In addition to the potassium and phosphate change, magnesium and manganese remained about only 5\%. Certain amount of zinc and calcium remained a little more. Toxic As and Cd were not present.

\begin{tabular}{|c|c|c|c|c|c|c|c|c|c|}
\hline Item & Unit & BR & LPBR & $\%$ remained & Item & Unit & BR & LPBR & \% Remained \\
\hline Energy & kcal/100g & 244 & 156 & 63.9 & Vitamin B1 & $\mathrm{mg} / 100 \mathrm{~g}$ & 0.12 & $<0.01$ & nd \\
\hline Water & $\mathrm{g} / 100 \mathrm{~g}$ & 40.7 & 62.2 & 152.8 & Arg & $\mathrm{mg} / 100 \mathrm{~g}$ & 240 & nd & 0 \\
\hline Carbohydrate & $\mathrm{g} / 100 \mathrm{~g}$ & 57.1 & 36.3 & 63.6 & Lys & $\mathrm{mg} / 100 \mathrm{~g}$ & 110 & nd & 0 \\
\hline Sugar & $\mathrm{g} / 100 \mathrm{~g}$ & 55.6 & 35.3 & 63.5 & His & $\mathrm{mg} / 100 \mathrm{~g}$ & 77 & nd & 0 \\
\hline Protein & $\mathrm{g} / 100 \mathrm{~g}$ & 1.3 & 0.2 & 15.4 & Phe & $\mathrm{mg} / 100 \mathrm{~g}$ & 140 & nd & 0 \\
\hline Lipid & $\mathrm{g} / 100 \mathrm{~g}$ & 1.9 & 1.3 & 68.4 & Tyr & $\mathrm{mg} / 100 \mathrm{~g}$ & 120 & 1 & 0.9 \\
\hline Ash & $\mathrm{g} / 100 \mathrm{~g}$ & 0.1 & 0.1 & 100.0 & Leu & $\mathrm{mg} / 100 \mathrm{~g}$ & 220 & nd & 0 \\
\hline Potassium & $\mathrm{mg} / 100 \mathrm{~g}$ & 85.3 & 0.5 & 0.6 & iLeu & $\mathrm{mg} / 100 \mathrm{~g}$ & 110 & nd & 0 \\
\hline Phosphate & $\mathrm{mg} / 100 \mathrm{~g}$ & 115 & 17 & 14.8 & Met & $\mathrm{mg} / 100 \mathrm{~g}$ & 66 & nd & 0 \\
\hline Dietary fiber & $\mathrm{g} / 100 \mathrm{~g}$ & 1.5 & 1.0 & 66.7 & Val & $\mathrm{mg} / 100 \mathrm{~g}$ & 160 & nd & 0 \\
\hline$\gamma$-oryzanol & $\mathrm{mg} / 100 \mathrm{~g}$ & 10.4 & 6.3 & 60.6 & Ala & $\mathrm{mg} / 100 \mathrm{~g}$ & 160 & nd & 0 \\
\hline NaCleq & $\mathrm{g} / 100 \mathrm{~g}$ & 0.0041 & 0.003 & 73.2 & Gly & $\mathrm{mg} / 100 \mathrm{~g}$ & 140 & nd & 0 \\
\hline $\mathrm{Na}$ & $\mathrm{mg} / 100 \mathrm{~g}$ & 2.5 & 1.8 & 72.0 & Pro & $\mathrm{mg} / 100 \mathrm{~g}$ & 130 & nd & 0 \\
\hline $\mathrm{K}$ & $\mathrm{mg} / 100 \mathrm{~g}$ & 85.3 & 0.5 & 0.6 & Glu & $\mathrm{mg} / 100 \mathrm{~g}$ & 470 & nd & 0 \\
\hline $\mathrm{Ca}$ & $\mathrm{mg} / 100 \mathrm{~g}$ & 6 & 6 & 100.0 & Ser & $\mathrm{mg} / 100 \mathrm{~g}$ & 140 & nd & 0 \\
\hline $\mathrm{Mg}$ & $\mathrm{mg} / 100 \mathrm{~g}$ & 47.5 & 2.2 & 4.6 & Thr & $\mathrm{mg} / 100 \mathrm{~g}$ & 100 & nd & 0 \\
\hline $\mathrm{P}$ & $\mathrm{mg} / 100 \mathrm{~g}$ & 115 & 17 & 14.8 & Asp & $\mathrm{mg} / 100 \mathrm{~g}$ & 260 & nd & 0 \\
\hline $\mathrm{Fe}$ & $\mathrm{mg} / 100 \mathrm{~g}$ & 0.4 & $<0.1$ & nd & Try & $\mathrm{mg} / 100 \mathrm{~g}$ & 42 & 2 & 4.8 \\
\hline $\mathrm{Zn}$ & $\mathrm{mg} / 100 \mathrm{~g}$ & 0.76 & 0.12 & 15.8 & Cys & $\mathrm{mg} / 100 \mathrm{~g}$ & 58 & nd & 0 \\
\hline $\mathrm{Cu}$ & $\mathrm{mg} / 100 \mathrm{~g}$ & 0.1 & $<0.1$ & nd & Antioxidant & & & & \\
\hline $\mathrm{Mn}$ & $\mathrm{mg} / 100 \mathrm{~g}$ & 0.83 & 0.05 & 6.0 & ORAC total & umole TE/g & 350 & 300 & 85.7 \\
\hline $\mathrm{As}_{2} \mathrm{O}_{3}$ & $<0.1 \mathrm{ug} / \mathrm{g}$ & 0 & 0 & 0 & ORAC hydrophilic & umole TE/g & 150 & 100 & 66.7 \\
\hline $\mathrm{Cd}$ & $<0.05 \mathrm{ug} / \mathrm{g}$ & 0 & 0 & 0 & ORAC lipophilic & umole TE/g & 200 & 200 & 100 \\
\hline
\end{tabular}

Table 1: Major and minor nutrients of Low-Protein Brown Rice.

BR; Brown rice before protein extraction. Biotech2020 used enzyme extraction and Lactobacillus fermentation. LPBR of Biotech shows the lowest protein contents. Remaining potassium is only $0.6 \%$, and that of phosphate is $14.8 \%$. While about two third of dietary fiber and $\gamma$-oryzanol are present. Antioxidant activity remains $85 \%$.

Degree of remaining minerals is various. $\mathrm{Ca}, \mathrm{Na}, \mathrm{Zn}$, then $\mathrm{Mn}$ and $\mathrm{Mg}$ remain, but Fe and Cu are lost. Almost all amino acids are lost, except Try and Tyr. 
Vitamins were also solved Vitamin B1 remained only as trace amounts. Only a small amount of tryptophan and tyrosine were detected among free amino acids.

Antioxidant activity of brown rice and LPBR remained 3-4 units in the boiled rice, mostly water-soluble AOU-L. AOU-P remained in the current LPBR. Polished rice did not show antioxidant activity at all [28].

Benefits of low protein rice and benefits of brown rice are conceptually shown in figure 3. In addition to the remaining carbohydrate (energy source), low protein, low potassium, low phosphate character of low protein rice, presence of dietary fiber, $\gamma$-oryzanol and antioxidant activity was the characteristic biomarkers of brown rice.

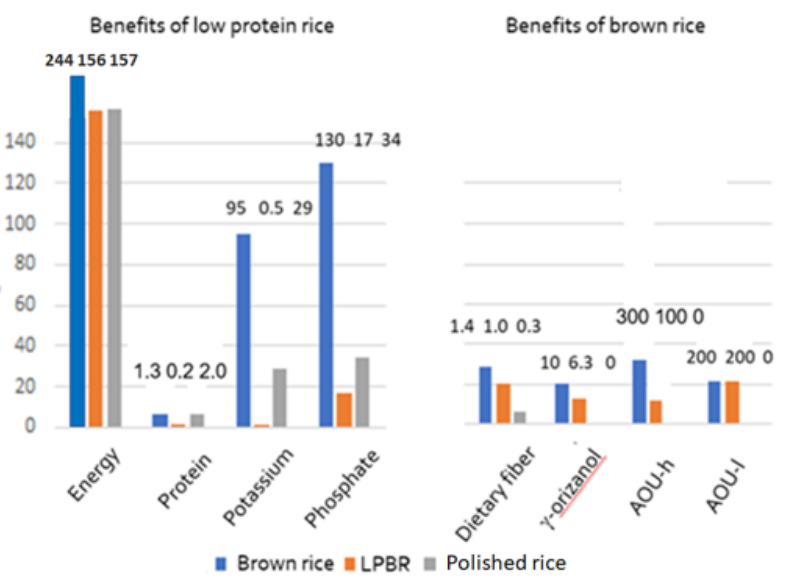

Figure 3: Comparison of nutrients in brown rice, LPBR and polished white rice.

Benefits of low protein rice are high energy content, low protein, low potassium and low phosphate. In addition, benefits of brown rice character are dietary fiber, $\gamma$-oryzanol and antioxidant activity.

\section{Discussion}

\section{Effect of Lactobacillus for LPBR production}

The combination of four steps was the optimal process to produce LPBR. In Lactobacillus fermentation, the ability to produce lactic acid was high, and the $\mathrm{pH}$ was rapidly reduced in the early stage of fermentation, resulting in an acidic environment. In the optimum pH range, the activity of protease increased, proteolysis was promoted, and a sharply decreased $\mathrm{pH}$ suppressed the growth of other bacteria.

The fermentation tank became anaerobic at an early stage when lactic acid bacteria enter the bran part. Because of carbon dioxide production, a gap appears between the bran and the endosperm, which was easily filled by enzymes and lactic acid bacteria. Lactic acid fermentation and proteolysis treatment at the site were efficient. Further ethanol production suppressed the growth of residual aerobic bacteria that were relatively resistant to lactic acid $[22,29]$.

\section{Nutrients evaluation of LPBR}

Early intervention through a low-protein diet is adequate to decrease proteinuria in CKD [29-33].

LPBR could make it easier to keep a regimen of 30 g protein/day with enough energy source intake [34]. In addition to decreased protein intake, CKD patients need to reduce their phosphorus and potassium intake [35]. Energy source intake was important to keep the efficiency of protein. We employed a simple estimate of necessary energy by $0.4 \mathrm{x}$ (kg body weight) unit, where one unit was 80 kcal [34].

LPBR meets all of these requirements as a staple food for CKD patients. Additional benefits should be obtained for the disease by dietary fibers, $\gamma$-oryzanol, ferulic acid, and antioxidant activity. Almost no potassium and low phosphate in LPBR were beneficial for the patients to prevent hyperkaliemia and hyperphosphatemia $[35,36]$.

A pack of LPBR contains $150 \mathrm{~g}$ LPBR (234 kcal), while the protein content is only $0.3 \mathrm{~g}$. When a patient eats three packs a day, he or she could intake $702 \mathrm{kcal}$ and only $0.9 \mathrm{~g}$ protein in total. Potassium was $2.25 \mathrm{mg}$, phosphate was $76.5 \mathrm{mg}$, and almost no $\mathrm{NaCl}$. In addition, the dietary fiber contents were $4.5 \mathrm{~g}, \gamma$-oryzanol 28.4 $\mathrm{mg}$, which could stabilize the intestinal environment and intestinal bacteria [37,38]. The antioxidant ability was $1350 \mu$ mole TEQ which activity was one-fourth of daily intake. Many phytochemicals contain antioxidants, which protect from damage caused by free radicals. The U.S. Department of Agriculture measured the antioxidant capacities of 326 food items. In fruits and vegetables, the ORAC values for the hydrophilic fractions (H-ORAC) were typically much higher than those of the lipophilic fractions (LORAC) [24]. LORAC remained in the current LPBR because the wax layer was protected. Consumption of rice is about $500 \mathrm{~g}$ a day as a staple food 
in daily meals should prevent carcinogenesis and diseases caused by free radicals [27].

These characteristics make LPBR the ideal staple food for CKD patients. In combination with soy protein for side dishes, it could help to achieve a tasty low protein diet [39].

\section{Conclusion}

A new low protein brown rice (LPBR) had both benefits of low-protein rice and brown rice itself, namely: dietary fibers, $\gamma-$ oryzanol, and antioxidant activity. The palatability is comparable to polished white rice. CKD is increasing worldwide, and recently it happened in an aging society and the diabetic complication and end-stage glomerulonephritis. A low-protein diet is the most effective intervention for the prevention of CKD. LPBR could provide enough energy with low protein, low potassium, low phosphate, and brown rice's health benefits by dietary fiber, $\gamma$-oryzanol, and antioxidant activity for CKD patients. LPBR could be available for patients with renal insufficiency at any stage.

\section{Acknowledgement}

The authors appreciate Dr. Philippe Calain, who cordially revised our manuscript and discussed about our work.

\section{Author Contribution}

All authors proceeded the work in consortium.

\section{Funding}

A part of this work was supported by the grant from the Medical Rice Association and the NARO Bio-oriented Technology Research (Innovation Technology).

\section{Conflict of Interest}

The authors had no conflict of interest to declare.

\section{Bibliography}

1. Jha V., et al. "Chronic kidney disease: global dimension and perspectives". Lancet 382 (2013): 260-272.

2. http://www.worldkidneyday.org/faqs/chronic-kidneydisease/

3. Zhang QL and Rothenbacher D. "Prevalence of chronic kidney disease in population-based studies: systematic review". BMC Public Health 8 (2008): 117.
4. Levey AS., et al. "Chronic kidney disease as a global public health problem: approaches and initiatives-a position statement from kidney disease improving global outcomes". Kidney International 72 (2007): 247-259.

5. El Nahas M. "The global challenge of chronic kidney disease". Kidney International 68 (2005): 2918-2929.

6. Zimmer P., et al. "Global and societal implications of the diabetes epidemic”. Nature 414 (2001): 782-787.

7. Atkins RC., et al. "World Kidney Day 2010: diabetic kidney disease-act now or pay later". American Journal of Kidney Diseases 55 (2010): 205-208.

8. Bilous R. "Microvascular disease: what does the UKPDS tell us about diabetic nephropathy?" Diabetic Medicine 25 (2000): 25-29.

9. Couser WG., et al. "The contribution of chronic kidney disease to the global burden of major non-communicable diseases". Kidney International 80 (2011): 1258-1270.

10. Watanabe S. "Low-protein diet for the prevention of renal failure". Proceedings of the Japan Academy, Series B 93 (2017): 1-9.

11. Dietary Reference Intake of Japanese (2020). https://www. mhlw.go.jp/stf/seisakunitsuite/bunya/kenkou_iryou/kenkou/eiyou/syokuji_kijyun.html

12. "Low-Protein Diets for Adults Without Diabetes Mellitus Who Have CKD". American Family Physician 102.11 (2020): 665666.

13. "Japan Nephrology Society Dietary recommendations for chronic kidney disease". Japanese Society of Nephrology (Nichijin-kai-shi) 56 (2014): 553-599.

14. Ministry of Health, Labour and Welfare. Standard of foods for diseased (2007).

15. Biotech Japan. "Low protein brown rice". Processing Methods P4443398 12 (2004).

16. Morita Y. "Proteins in rice seeds". Nippon Jozou Kyokai 67.10 (1972): 843-847.

17. Tanaka $\mathrm{K}$ and Masumura T. "Mechanisms of protein accumulation in rice crop". Kagaku to Seibutsu 26.8 (1988): 543-550.

18. Minakuchi S and Nakaya N. "New rice varieties with low levels of easy-to-digest protein”. 'Himeiku 83’ Bull. Ehime Res. Inst. Agric. Forest. Fish. 
19. Saika $\mathrm{K}$ and Watanabe $\mathrm{S}$. "Producing rinse-free rice by the bran-grind method: A way to stop environmental pollution from rice industry wastewater". Advances in Food Technology and Nutritional Sciences - Open Journal 3.1 (2017): 45-50.

20. Hoshino H and Gochou H. "Change of the bacteria by the difference of washing times and preservation condition to cooled rice". Seitoku Eiyo Tanki Daigaku Kiyou 6 (2014): 11-17.

21. Sakuma K., et al. "Effect of cooking water $\mathrm{pH}$ on commercial sterility in the production of cooked rice packed under semiaseptic condition. Nihon Shokuhin Kogyo Kaishi 9.3 (2008): 157-165.

22. Japan Food Research Laboratory (2020). http://www.jfrl. or.jp/

23. Food Analysis Technology Center SUNATEC, Yokkaichi-shi, Mie (2020).

24. NIH National Center for Complementary and Integrative Health. Antioxidants: In-Depth (2020).

25. Terashima M., et al. "New method to evaluate water-soluble antioxidant activity based on protein structural change". Journal of Agricultural and Food Chemistry 55.1 (2007): 165-169.

26. Watanabe J., et al. "Method validation by interlaboratory studies of improved hydrophilic oxygen radical absorbance capacity methods for the determination of antioxidant capacities of antioxidant solutions and food extracts". Annals of Science 28.2 (2012): 159-165.

27. Takei N., et al. "Low-protein rice (LPR) product: Processing method and product safety". Advances in Food Technology and Nutritional Sciences - Open Journal 3.1 (2017): 33-41.

28. Watanabe S., et al. "Medical rice: a new wax-free brown rice and its protein reduced rice". Advances in Food Technology and Nutritional Sciences - Open Journal 4.1 (2018): 10-16.

29. van der Velde M., et al. "Screening for albuminuria identifies individuals at increased renal risk". Journal of the American Society of Nephrology 20 (2009): 852-862.

30. Romundstad S., et al. "Microalbuminuria, and all-cause mortality in 2,089 apparently healthy individuals: a 44-year followup study. The Nord-Trondelag Health Study (HUNT), Norway". American Journal of Kidney Diseases 42 (2003): 466-473.

31. Gansevoort RT and de Jong PE. "The case for using albuminuria instaging chronic kidney disease". Journal of the American
Society of Nephrology 20 (2009): 465-468.

32. Verhave JC., et al. "An elevated urinary albumin excretion predicts de novo development of renal function impairment in the general population". Kidney International 66 (2004): S18-S21.

33. Reutens AT. "Epidemiology of diabetic kidney disease". Medical Clinics of North America 97 (2013): 1-18.

34. Hirakawa A., et al. "Comprehensive food labeling for obesity control". Advances in Obesity, Weight Management and Control's 4 (2016): 00088.

35. Watanabe S., et al. "A cross-sectional study on the effects of long term very low protein diets in patients with chronic kidney disease. Serum and urine DEXA and amino acid profiles". Anti-aging Medicine 7 (2010): 7-13.

36. Williams PS., et al. "Failure of dietary protein and phosphate restriction to retard the rate of progression of chronic renal failure: a prospective, randomized, controlled trial". Q. J. Medicine 81.294 (1991): 837-855.

37. Hirakawa A., et al. "The nested study on the intestinal microbiota in Genki Study with special reference to the effect of brown rice eating". Journal of Obesity and Chronic Diseases 3.1 (2019): 1-13.

38. Kikuchi K., et al. "Changes in microbiota and short-chain fatty acids following 3-month pilot intervention study feeding brown rice ball (Omusubi) to healthy people". La Prensa Medica Argentina 107 (2020): 1-11.

39. Azadbakht L., et al. "Soy protein intake, cardiorenal indices, and C-reactive protein in type 2 diabetes with nephropathy:

\section{Volume 5 Issue 8 August 2021}

(C) All rights are reserved by Shaw Watanabe., et al. 